\title{
Wine Production from Mixed Fruits (Pineapple and Watermelon) Using High Alcohol Tolerant Yeast Isolated from Palm Wine
}

\author{
Okeke, B.C, Agu, K.C.", Uba, P.O., Awah, N.S., Anaukwu C.G., Archibong, E.J., \\ Uwanta, L.I., Ezeneche, J.N. Ezenwa, C.U. Orji, M.U.
}

Department of Applied Microbiology and Brewing, Nnamdi Azikiwe University, Nigeria

Copyright (C) 2015 by authors, all rights reserved. Authors agree that this article remains permanently open access under the terms of the Creative Commons Attribution License 4.0 International License

\begin{abstract}
Mixed fruit wine (pineapple and watermelon) was produced using Saccharomyces cerevisiae isolated from palm wine. Primary and secondary fermentation of the fruits lasted for 7 and 28 days respectively, during which aliquot samples analysis of $p H$, titrable acidity, specific gravity, alcohol content and reducing sugar were carried out using standard procedures. Specific gravity of the wine was observed to reduce drastically as the fermentation progresses. The $p H$ of the fruit must during the period of fermentation ranged from 3.0 to 4.46 . During the fermentation period, consistent increase in alcohol content was observed with time. At the end of the $28^{\text {th }}$ day of fermentation, the alcohol content was observed to be $3.2 \%$. The titrable acidity of the wine was observed to show steady trend with time throughout the period of fermentation. This study showed that acceptable wine can be produced from mixed fruits pineapple and watermelon using yeasts especially Saccharomyces cerevisiae isolated from palm wine.
\end{abstract}

Keywords Wine, Palm Wine, Pineapple, Watermelon, Yeast, Fermentation

\section{Introduction}

Wine is any alcoholic beverage produced from juices of variety of fruits by fermentative action of microorganisms either spontaneously or seeding with a particular strain mainly of yeast species to adopt a particular quality of wine. Wine is one of the most recognizable high value added products from fruits.

Most commercially produced wines are usually made from fermented grapes; this fermentation process is not done by introducing any chemicals or sugar but by adding different species of yeast to the crushed grapes. Yeast has the capability of converting grapes into an alcoholic compound and removing the sugar content in it for the production of different types of wines. Sometimes wines are produced from different types of fruits like; Paw-Paw, mango, Pineapple, Banana, Lemon, Watermelon etc., here the wine so produced bears the name of the fruit or fruit mixture used in its production ${ }^{1}$.

In the European Union, wine is legally defined as the fermented juice of grapes ${ }^{3}$. Wine can be made from virtually many plant matters that can be fermented ${ }^{3}$. Most fruits and berries have the potential to produce wine. Wine making involves the use of yeast to ferment the 'must' of a chosen fruit or fruits for a number of days, depending on the objective of the winemaker. The yeast which is the main organism responsible for alcoholic fermentation usually belongs to the genus Saccharomyces.

Palm wine is the fermented sap of the tropical plant of the palmae family. It is produced and consumed in very large quantities in the Southeastern Nigeria. It contains nutritionally important components including amino acids, proteins, Vitamins and sugar ${ }^{2}$. These make this wine a veritable medium for the growth of a consortium of microorganisms, where growth in turn, change the physicochemical conditions of the wine giving rise to competition and succession of organism. Ogbonna (1984) and Onyedinma (1983) used palm wine isolates of Saccharomyces cerevisiae to produce artificial palm wine and beer, respectively.

Palm wine is tapped from the sap of Elaesi Species and the sap of Raphia Species which contains a heavy suspension of live yeasts and bacteria ${ }^{2}$. Most studies on palm win have reported its potentials are source of yeast isolate for the fermentation industries. Okafor, (2007) in his study isolated seventeen yeast strains, four belonging to the species of Candida, twelve to the genus of Saccharomyces and one to Endomycopsis species.

The objective of this study is to produce wine from mixed fruits: Pineapple and Watermelon to study the fermentation 
process of the wine and encourage its occurrence. $p \mathrm{H}$, temperature, Reducing sugar and filterable acidity tests were all analyzed quantitatively in the course of this work.

\section{Materials and Methods}

\subsection{Sample Collection}

Ripe watermelon fruits (Citrullus lanatus var lanatus) and pineapple fruits (Ananas comosus) were bought from Eke Market, Awka, Anambra State. The fruits were washed thoroughly with sterile water and rinsed with deionized water containing $0.1 \%$ formaldehyde. Fresh palm wine was obtained from a palm wine tapper in Amanseavillage, Awka, Anambra State, Nigeria.

\subsection{Isolation of Yeast from Palm Wine}

Fresh palm wine was obtained from Amensea village Awka, Anambra State and fermented for 24hours. The fresh palm-wine was allow to sediment and the sediment was inoculated onto Malt extract agar in duplicates. The plates were incubated at room temperature for 24 hours. Developing isolates were purified by repeated subculture techniques and slides of pure culture were prepared for microscopic observation and identification using lactophenol cotton blue and the pure cultures were identified by their morphological characteristics.

\subsection{Inoculum Development}

The pineapple and watermelon were washed thoroughly with $0.1 \%$ sodium metabisulphite in water. The fruits were cut, manually deseeded, blended and filtered to obtain the juice. About $200 \mathrm{ml}$ of the juice $(100 \mathrm{ml}$ of pineapple juice and $100 \mathrm{ml}$ of Water melon juice) were introduced into a clean sterile $500 \mathrm{ml}$ conical flask and sterilized by autoclaving. Upon cooling, 3 loopful of the yeast culture isolated from the palm-wine was used to inoculate the juice and incubated in a rotary shaker for 48 hours.

All procedures were done under aseptic condition.

\subsection{Must Fermentation}

The pineapple and watermelon were washed thoroughly with $0.1 \%$ sodium metabisulphite in water. The fruits were cut, manually deseeded, blended and filtered to obtain the must.Aliquots of the extracted juice obtained and used for $\mathrm{pH}$, temperature, titrable acidity and reducing sugar analysis.

The must was transferred into a sterile $500 \mathrm{ml}$ glass fermenter, until it was $3 / 4$ filled. This was followed by the addition of $0.4 \mathrm{~g}$ Sodium metabisulphite, $100 \mathrm{~g}$ of granulated sugar (for fortification), $29.4 \mathrm{~g}$ of $0.84 \%$ Ammonium sulphate $4.2 \mathrm{~g}$ of $0.12 \%$ potassium dihydrogen for yeast supplementation. The juice was inoculated with yeast obtained by inoculum development and the set-up allowed to ferment for 28 days, with daily analysis of parameters such as: $p H$, temperature, reducing sugar and titrable acidity.

\subsection{Physiochemical Analyses}

\section{pH Determination}

Ten $\mathrm{ml}$ of the "must" was put into a sterile beaker, and the $\mathrm{pH}$ of the must determine using a $\mathrm{pH}$ a digital $\mathrm{pH}$ meter (Model No: pH S-25)

\subsection{Determination of Reducing Sugar}

The quantitative estimation of reducing sugar of the wine was determined using the method described by Miller (1971). One $\mathrm{ml}$ of 3,5-Dinitrosalicyclic acid (DNS) was added to $1 \mathrm{ml}$ of supernatant of sample, in a test tube and the mixture heated in boiling water for 10 minutes. The test tube was cooled rapidly in tap water and the volume adjusted to $12 \mathrm{ml}$ with distilled water. A blank containing $1 \mathrm{ml}$ of distilled water and $1 \mathrm{ml}$ of DNS was prepared. The optical density of the sample was read against the blank in the spectrophotometer or 540nm absorbance. The concentration of reducing sugar in the supernatant was estimated from the glucose standard curve.

\subsection{Determination of Specific Gravity}

Fifty $\mathrm{ml}$ specific gravity bottle was thoroughly cleaned with distilled water, dried in an oven for $50^{\circ} \mathrm{C}$ and allowed to cool. The weight of the cooled dried bottle $\left(\mathrm{W}_{1}\right)$ was recorded. The dried bottle was filled with deionized water and surface of the bottle was cleaned with a cotton wool and weighed as $\left(\mathrm{W}_{2}\right)$.

The bottle was empty and cleaned twice with $10 \mathrm{ml}$ of the "must" thereafter the bottle was filled to the brim with the "must" and the bottle cleaned with cotton wool and weighed as $\left(\mathrm{W}_{3}\right)$. The specific gravity (S.G) was calculated

$$
S . G=\frac{W_{3}-W_{1}}{W_{2}-W_{1}}=\frac{S}{W}
$$

Where

$\mathrm{S}=$ weight of volume of must $\left(\mathrm{W}_{3}-\mathrm{W}_{1}\right)$

$\mathrm{W}=$ weight of volume of water $\left(\mathrm{W}_{2}-1\right)$

\subsection{Estimation of Titrable Acidity}

This was determined by the methods described by Amerine and $\mathrm{Ough}^{14}$. $200 \mathrm{ml}$ of distilled water was introduced into a sterile $500 \mathrm{ml}$ conical flask and boiled. $1 \mathrm{ml}$ of $1 \%$ aqueous alcoholic phenolphthalein indicator solution was added. This was titrated with $0.1 \mathrm{M} \mathrm{NaOH}$ solution to give a faint pink colour. $5 \mathrm{ml}$ of the "must" was pipette and introduced into the boiling neutralized solution and titrated again to the end point using the same $0.1 \mathrm{M} \mathrm{NaOH}$ solution.

The titrable acidity was expressed as tartaric acid and was calculated thus: 


$$
\text { Tartaric acid } g / 100 m l=\frac{V \times M \times 75 \times 100}{100 \times V}
$$

Where;

$\mathrm{V}=$ Volume of $\mathrm{NaOH}$ (final reading- initial reading).

$\mathrm{M}=$ Molarity of $\mathrm{NaOH}$

$\mathrm{V}=$ Volume of "must"

\section{Results}

Table 1. Analysis of the fruit Juice

\begin{tabular}{|c|c|c|c|}
\hline Parameters & & Mean values \pm S.D & \\
\hline & Pineapple & Watermelon & Mixed juice \\
\hline pH & $4.22 \pm 0.01$ & $5.07 \pm 0.01$ & $4.47 \pm 0.01$ \\
\hline Reducing sugars & $0.80 \pm 0.00$ & $0.81 \pm 0.00$ & $0.71 \pm 0.00$ \\
\hline Specific gravity & $43.91 \pm 0.01$ & $43.04 \pm 0.06$ & $40.93 \pm 0.04$ \\
\hline
\end{tabular}

Table 2. Protein and Moisture content values of Pineapple and Watermelon

\begin{tabular}{|c|c|c|}
\hline Parameters & Values (mean \pm S.D) & \\
\hline & Pineapple (per 100g) & Watermelon (per 100g) \\
\hline Protein content & $0.55 \pm 0.01$ & $0.62 \pm 0.01$ \\
\hline Moisture content & $86.05 \pm 0.07$ & $91.46 \pm 0.01$ \\
\hline
\end{tabular}

Throughout the period of fermentation, $p H$ of the must was within the acidic range. This was irrespective of the yeast strain used for fermentation. $p H$ ranged from 4.46 to 3.2 (Fig.1). As shown in Fig.1, a steady increase in alcohol content was observed in the fruit wine throughout the period of fermentation with the fermenting yeast strain. The increases were irrespective of the yeast strain and the fruit used. At the end of the $28^{\text {th }}$ day, of the fermentation, the concentration of alcohol in the fruit wines were observed to range from $0 \%$ to 3.0 .

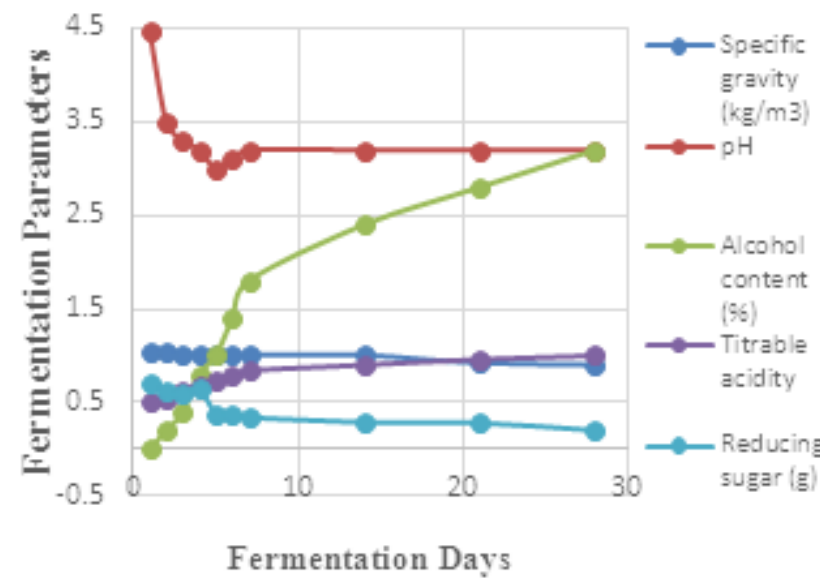

Figure 1. Wine Analyses

In the case of specific gravity of the fruit wine gradual decrease in valves were observed throughout the period of fermentation. These decreases were observed to be irrespective of the yeast strain and the fruits used in the wine production. Between 21 days to 28 days of the fermentation, specific gravity valves were observed to range from 0.922 to $0.901 \mathrm{kgm}^{-3}$.

Fig. 1 also showed the trend in titrable acidity, this was observed to show a steady increase with time throughout the period of fermentation. At the $28^{\text {th }}$ day of fermentation, acid concentration in the fruit wine was observed to increase from the initial concentration ranges of $0.55 \%$ to $1.01 \%$. In the case of reducing sugar of the wine during the period of fermentation, the values of the reducing sugar of the wine were observed to be decreasing. It was high on the first day which was the start of the wine fermentation and due to the presence of sugar in the fermenting wine, the reduction in the reducing sugar is due to the activities of the fermenting yeast on the wine and the production of alcohol. The reducing sugar ranged from $0.712 \mathrm{~g}$ on the first day to $0.202 \mathrm{~g}$ on the $28^{\text {th }}$ day.

\section{Discussion}

In this research work, the choice of the fruits: Pineapple and Watermelon were deliberate. From table 1, it was observed that the moisture content of the fruits ranged from $86 \mathrm{~g}$ to $91.45 \mathrm{~g}$ and accounts for their high perishable nature and their short shelf life under normal storage condition ${ }^{6}$.The fruits contained reasonable amount of carbohydrate, which gives an account of their high caloric value.

This work has shown that the $\mathrm{pH}$ ranges of the pineapple, watermelon, and mixed fruit juice used for the production of the wine for this research were $4.22 \pm 0.01,5.07 \pm 0.01$ and $4.47 \pm 0.01$ respectively, while there was no significant difference in the values of the reducing sugars amongst the three samples. In the case of Specific Gravity, there was no obvious difference between pineapple and watermelon, but diifered slightly with the value obtained for mixed fruits.

Also revealed are consistent increases in acidity (titrable) of the wine throughout the period of fermentation. Studies have shown that during fermentation of fruits, low $\mathrm{pH}$ is inhibitory to the growth of spoilage organisms but creates conducive environment for the growth of desirable organisms. Also, low $\mathrm{pH}$ and high acidity are known to give fermenting yeasts competitive advantage in natural environments ${ }^{4}$. The titrable acidity of the final wine is expected to be between 0.5 to $1.0 \%$.

In this study, the results of titrable acidity of the wine fell within this limit.In order to supplement the sugar content of the "musts" granulated sugar which is from cane sugar and a source of "sucrose" was part of the additives. Reports have shown that the major problem associated with the use of tropical fruits in wine production is their low sugar content ${ }^{8}$.

Remarkable amount of alcohol was produced from the fruit wines during fermentation with the yeast strain used. This trend was consistent during the course of fermentation.

In general, the percentage alcohol produced from the fruits used for the fermentation by the yeast strain was above $2 \%$ which is comparable with moderate grape wines ${ }^{9,5,11}$. The 
performance and potential of the yeast strain as substituent for the commercial baker's yeast was measured by the amount of alcohol produced. High alcohols are known to be important precursors for the formation of esters, which are associated with pleasant aromas ${ }^{10}$.

In the present study, the amount of alcohol produced by the isolate the yeast from the palmwine did not show any difference from palm wine ${ }^{10}$.

Reports have shown that alcoholic fermentation leads to a series of by-products in addition to ethanol. Some of the by-products include carbonyl compounds, alcohols, esters, acids and acetals, all of them influencing the quality of the finished product. The composition and concentration levels of the by-products can vary widely $(\mathrm{mg} / \mathrm{L}$ to hundreds of $\mathrm{mg} / \mathrm{L})^{12,13}$.

In this study, $p H$ of the fruit wine throughout the period of fermentation ranged from 3.0 to 3.5. A similar observation has been reported by Reddy and Reddy; in their study on mango fruit, Optimum $p H$ value for quality wine production was $4.0^{4}$.

The specific gravity of the fruit wine produced in this study reduces as the fermentation days of the wine increases.

After the 28 days fermentation the specific gravity of the wine reduced drastically to $0.901 \mathrm{kgm}^{-3}$ this was due to the type of yeast used in the wine production. Saccharomyces cerevisiae isolated from palm wine has been reported to reduce specific quality of fruit wines during fermentation? The short shelf-life of beverages are however a major problem faced by their producers and consumers in Africa $^{32,33}$.

The specific gravity values of the wine were observed to diminish by significant value of $\mathrm{p} \leq 1.01 \pm 0.011$. The type and aroma produced during wine production is reported to depend on yeast, environmental factors and physico-chemical characteristics of the "musts".

\section{Acknowledgements}

I acknowledge the entire Laboratory staff of the Department Of Applied Microbiology and Brewing for their efforts in the Isolation, characterization and identification of the Yeast (Saccharomyces cerevisiae) used for this study.

\section{REFERENCES}

[1] Robinson, J. (2006). The Oxford Companion of wine $\left(3^{\text {rd }}\right.$ Edition) Oxford University Press,. $268-780$.

[2] Okafor, N. (2007). Modern Industrial Microbiology and Biotechnology. Science Publishers, Enfield, 263-308.

[3] Harding, G. (2005). "Wine Miscellany". Clarkson Potter Publishing New York. 5-9

[4] Reddy, L.V.A. and Reddy, O.V.S. (2005). Production and Characterization of wine from mango fruit (Mangifera indica
L). World Journal of Microbiology and Biotechnology, 21:1345-1350.

[5] Querol, A., Fernandez-Ezpinar, T.M., Olmmo, M.L. and Barrio, E. (2003). Adaptive evolution of wine yeast. International Journal of Food Microbiology, 86:3-10

[6] Okafor, N. (1972). Palm wine Yeast from parts of Nigeria. Journal of Food Science and Agriculture.23:1399-1407.

[7] Okafor, N. (2007). "The technology of passion fruit and Pawpaw wines". American Journal of Enology and Viticulture, 17:27.

[8] Alobo, A.P and Offonry, S.U. (2009). Characteristics of coloured wine produced from Roselle I (Hibiscus sabdariffa) calyx extract. Journal of Institute of Brewing, 115(2):91-94.

[9] Ayogu, T.E. (1999). Evaluation of the performance of yeast isolated from Nigerian palm wine in wine production from pineapple fruits. Journal of Bioresources and Technology, 69:189-190.

[10] Clement-Jimenez, J.M., Mingorance-Cazorla, L., Mortinez-Rodriguez, S., Heras-Vazques, F.J.L. and Rodriguez-Vicon F. (2005). Influence of sequential yeast mixtures wine fermentation. International Journal of Microbiology, 98:301-308.

[11] Okunowo, W.O., Okotore, R.O. and Osuntoki, A.A. (2005). The alcoholic fermentative efficiency of indigenous yeast strains of different origin on orange juice. African Journal of Biotechnology, 4:1290-1296.

[12] Plutowska, B. and Wardenaki, W. (2008). Application of gas chromatography-ufactometry(GceO) in analysis and quality assessment of alcohols beverages- a review. Journal of Food Chemistry, 107(1):449-463.

[13] Duarte, W.F, Dias, D.R, Oliveira, M.J., Teixeira, J.A, Silva, J.D., and Schwan, R.F (2010). Characterization of different fruit wines made from Cacao, cupuassv, gabiroba, umby and jaboticaba. Journal of Food Science and Technology,30:1-9.

[14] Amerine, M. A. and Ough, C.S. (1980). Methods for analysis of must and wines. John Wiley and Sons, LTD, New York, Ny. Pp. 300-315.

[15] Onyedinma, J. (1983). Production of Palm wine analogue from synthetic medium. Thesis, University of Nigeria, Nsukka, 10-11

[16] Svan, P. (2008). Preservatives in Wine and why we need them. http://ezinearticles. Com. Accessed on $29^{\text {th }}$ June, 2015.

[17] Coppens d' Eeckenbrugee, G. and Freddy, S.L. (2003). Morphology, Anatomy and Taxonomy of Pineapple In: Bartholomew, D.P., Paul, R.E and Rohrbach, K.G. "Botany Production and uses of Pineapple" Wallingford, UK. 21 -22

[18] Dunn, B., Levine, R.P. and Shelock, G. (2005). Microarny. Karyotyping of commercial wine yeast strains, 6(1): 53-57

[19] FAO (2009). Division of statistics: UN food and Agriculture Organization Coporate Statistical Database http://www.fao.org/staticticedatabase. accessed on 14th July, 2015

[20] Van Rij, K. (1984). The yeast. A Taxonomic Study. $3^{\text {rd }}$ Edn, Elsevier Amsterdam, Amsterdam, pp: 55-57.

[21] FAO (2002). Tropical foods commodity notes, Statistical 
Database. http://www.fao.org/staticticedatabase. accessed on 14th July, 2015

[22] Fleet, G.H. (2003). Yeast interaction and wine flavor. International Journal of food microbiology, 86:11-22.

[23] Figueroa, A., Sanchez- Gonzales, M.A., Wong, A and Arymond, B.H. (2012). "Watermelon extract Supplementation". American Journal of Hypertension, 25(6):640-643

[24] Gonzales, T., Jubany, A.S., Carrau, F.M. and Gaggen, C. (2001). Differentiation of Industrial wine yeast strains using Microsatellite markers. Letters in Applied Microbiology, 33(1):11-75.

[25] Hawkins, R. (2007). "James, D. Dole and the 1932 failure of the Hawaiian Pineapple Company". Hawaiian Journal of History, 41: 149-170.

[26] Izuagbe, Y.S (1982). Malo-lactic fermentation of Leuconostoc species isolated from Oregon wine. http://www-fao.org/docrep. Accessed on 11th July, 2015.

[27] McBryde, C., Gardner, J. M., De Barros Lopes, M. and Jiranek, V. (2006). Generation of novel wine yeast strains by adaptive evolution. American Journal of Enology and Viticulture. 81-85
[28] Okegbile, E.O. and Taiwo, E.A. (1990). The Nutritional potential of black relvet, Nigeria. Journal of Nutritional Science, 8:115-121

[29] Pearson, D. (1981). The chemical Analysis of foods. Churchi//Living Stone, Edinburgh, 353-355.

[30] Toro, M.E. and Vazquez, F. (2002). Fermentation behavior of controlled mixed and sequential cultures of Candida cantarelli and Saccharomyces cerevisiae wine yeasts. World Journal of Microbiology and Biotechnology, 18:347-354

[31] Zohany, D. and Hopf, M. (2000). Domestication of plants in the Old World, ( $3^{\text {rd }}$ edition), Oxford University Press, 193-200.

[32] Mbachu, A.E., Etok, C.A., Agu, K.C., Okafor, O.I., Awah, N.S., Chidi-Onuorah, L.C., Ekwueme, V.C., Okpala, J., Ogbue, M.O. and Ikele M.O. (2014). Microbial quality of kunu drink sold in Calabar, Cross River State, Nigeria. Journal of Global Biosciences, 3(2): 511-515.

[33] Anaukwu, C.G., Nwangwu, F.C., Okafor, I.O. Ezemba, C.C. Orji, C.C. Agu, K.C. and Archibong, J.E. (2015). Microbiological analysis of Burukutu beverage produced in southern part of Nigeria. European Journal of Experimental Biology, 5(8):18-22 